\title{
The Wernicke conundrum revisited: evidence from connectome- based lesion-symptom mapping in post-stroke aphasia
}

\author{
William Matchin ${ }^{1 *}$, Dirk-Bart den Ouden ${ }^{1}$, Gregory Hickok ${ }^{2}$, Argye E. Hillis ${ }^{3}$, Leonardo \\ Bonilha $^{4}$, Julius Fridriksson ${ }^{1}$
}

${ }^{1}$ Dept. of Communication Sciences and Disorders, University of South Carolina

${ }^{2}$ Dept. of Cognitive Sciences, Dept. of Language Science, University of California, Irvine ${ }^{3}$ Dept. of Neurology, Johns Hopkins University School of Medicine and Dept. of Cognitive Science, Johns Hopkins University

${ }^{4}$ Dept. of Neurology, Medical University of South Carolina

*Corresponding author

915 Greene St., Discovery 1, Room 202D, Columbia, SC 29208, USA

Email: matchin@mailbox.sc.edu

Tel: +1 803-777-9240

\begin{abstract}
The classical assumption that word and sentence comprehension deficits in stroke aphasia follow from damage to Wernicke's area has been questioned following discrepant results in primary progressive aphasia. We tested the hypothesis of Mesulam et al. $(2015 ; 2019)$ that word and sentence comprehension deficits in stroke aphasia result from 'double disconnection' due to white matter damage: word comprehension deficits resulting from disconnection of the anterior temporal lobe and sentence comprehension deficits resulting from disconnection of the frontal lobe. We performed lesion-deficit correlations, including connectome-based lesion-symptom mapping, in four large, partially overlapping groups of English-speaking chronic left hemisphere stroke survivors. After removing variance due to object recognition and associative semantic processing, the same middle and posterior temporal lobe regions were implicated both in word comprehension deficits $(\mathrm{N}=180)$ and complex noncanonical sentence comprehension deficits $(\mathrm{N}=131)$. Repetition deficits $(\mathrm{N}=218)$ were associated with damage to the posterior temporal lobe and superior longitudinal fasciculus, and agrammatic production $(\mathrm{N}=92)$ was associated with damage to the posterior middle frontal gyrus. Connectome lesion-symptom mapping revealed similar temporal-occipital white matter disconnections for impaired word and noncanonical sentence comprehension, including the temporal pole. We found additional significant temporal-parietal disconnections for noncanonical sentence comprehension deficits, which may indicate a role for phonological working memory in processing complex syntax, but no significant frontal-temporal or frontal-parietal disconnections. By contrast, repetition deficits were associated with a very large set of significant disconnections, including frontal-temporal disconnections, and agrammatic production was associated primarily with significant disconnections within the frontal lobe. Our results largely agree with the classical notion that damage to Wernicke's area causes both word and sentence comprehension deficits in stroke-
\end{abstract}


based aphasia, suggest a supporting role for temporal pole in both word and sentence comprehension, and speak against the hypothesis that sentence comprehension deficits in Wernicke's aphasia result from frontal-temporal or frontal-parietal disconnections.

Keywords: aphasia; lesion-symptom mapping; connectome; word comprehension; noncanonical sentence comprehension; syntax; stroke; Wernicke's area

\section{Introduction}

The classical model of language in the brain posits a primary role for Wernicke's area in both word and sentence comprehension (Geschwind, 1972, 1979; Lichtheim, 1885; Wernicke, 1874). The major motivation for the primacy of Wernicke's area in word and sentence comprehension is the notable comprehension deficits in Wernicke's aphasia, typically involving posterior temporal-parietal damage (Damasio, 1992; Hillis, 2007), which roughly corresponds to the region classically associated with Wernicke's area (Bogen \& Bogen, 1976; Tremblay \& Dick, 2016).

Recently, the classical view has been questioned from the perspective of primary progressive aphasia (PPA). Mesulam et al. (2015) performed a voxel-based morphometry (VBM) study in 72 people with PPA on word and sentence comprehension. Their sentence comprehension task minimized lexical access demands by using sentences with highly frequent words (e.g., boy, girl, dog, cat, kiss, chase) and noncanonical structures (object-first sentences such as passives, which do not conform to expected word order), to emphasize grammatical processing. By contrast, their word comprehension task (PPVT) maximized lexical-semantic demands, and the variance due to object recognition and non-verbal semantics was factored out using the Pyramids and Palm Trees test (PPT; Howard \& Patterson, 1992) as a covariate. They found no association of posterior temporal-parietal atrophy with word comprehension deficits and minimal association of atrophy in this region with deficits in noncanonical sentence comprehension. By contrast, atrophy of the anterior temporal lobe (ATL), primarily the temporal pole, was strongly associated with word comprehension (but not sentence comprehension) impairment, whereas inferior parietal and frontal degeneration was associated with sentence comprehension (but not word comprehension) impairment. Mesulam et al., (2019) followed up this study by showing that repetition (but not word comprehension) was associated with degeneration within superior posterior temporal and inferior parietal lobes. Overall, they associated the temporal-parietal territory commonly attributed to Wernicke's area with a phonological working memory function, not critical for basic aspects of linguistic processing.

To explain the discrepancy of their results with the literature on Wernicke's aphasia, Mesulam et al. (2015) posited a "double disconnection" hypothesis. Given that strokes often impinge on white matter, and that disconnection due to white matter damage can impair language abilities independently of cortical grey matter damage (Bonilha et al., 2014; Fridriksson et al., 2007), they suggested that lesions to temporal-parietal cortex may impair both word and sentence comprehension deficits not through damage to the relevant cortical centers themselves but through disconnection (Catani \& Mesulam, 2008). In light of their VBM results in PPA, they suggested that the ATL is the key region underlying word comprehension and that frontal cortex 
(primarily Broca's area) is the key region for sentence/syntactic processing, both of which may be disconnected due to posterior temporal-parietal strokes.

There two problems with this logic. First, functional neuroimaging studies have shown that the spatial location and extent of activation of syntactic processing and lexical access are remarkably similar (for a meta-analysis and review, see Hagoort \& Indefrey, 2014, for a more recent review see Matchin \& Hickok, 2020). This includes the posterior superior temporal sulcus (STS) and posterior MTG, falling within the traditional Wernicke's territory. Regardless of the explanation for this overlap (Fedorenko et al., 2020; Matchin \& Hickok, 2020), it suggests that coinciding word and sentence comprehension deficits should follow from damage to this region.

Second, a large body of LSM studies in post-stroke aphasia have shown that damage to Broca's area, and inferior-posterior prefrontal frontal cortex more generally, is not reliably implicated in sentence or syntactic comprehension deficits (Dronkers et al., 2004; Pillay et al., 2017; Race et al., 2012; Rogalsky et al., 2018; Thothathiri et al., 2012; Wilson \& Saygin, 2004). There may be a minor supporting role for frontal cortex in supporting the processing of particularly difficult sentence structures (Den Ouden et al., 2012), although the location of the lesion correlates of such deficits is inconsistent (Amici et al., 2007; Dronkers et al., 2004; Fridriksson et al., 2018; Magnusdottir et al., 2013; Wilson et al., 2011) (for a review, see Matchin \& Hickok, 2020). If noncanonical sentence comprehension deficits in Wernicke's aphasia are primarily due to disconnection of Broca's area from the rest of the language network, then one would expect frontal lesions including Broca's area to also impair syntactic comprehension. However, this is not a pattern that is reliably seen, in contrast to that associated with posterior temporal-parietal damage, which reliably predicts sentence comprehension impairments (Baldo \& Dronkers, 2007; Dronkers et al., 2004; Fridriksson et al., 2018; Magnusdottir et al., 2013; Pillay et al., 2017; Rogalsky et al., 2018; Thothathiri et al., 2012).

For these reasons, the dissociation, both in behavior and lesion correlates, between word and sentence comprehension in PPA reported by Mesulam et al. (2015) is surprising and deserves scrutiny. We examined these issues, testing the hypothesis of Mesulam et al. that overlap of word and sentence comprehension deficits in post-stroke aphasia is due to distinct disconnection patterns. We analysed data in a large group of people with post-stroke aphasia using LSM as well as connectome-based lesion-symptom mapping (CLSM), which uses diffusion tensor imaging to ascertain the strength of white matter connections between regions associated with behavioral scores (Bonilha et al., 2017; Del Gaizo et al., 2017; Yourganov et al., 2016). In a previous report (Bonilha et al., 2017), our research group performed LSM and CLSM analyses of word comprehension alone (with PPT as a covariate) in a smaller group of subjects (43), finding that impaired word comprehension was associated with damage to the inferior temporal gyrus and disconnection between posterior middle temporal gyrus and inferior temporal gyrus. A follow-up study (Hillis et al., 2017) expanded the number of subjects (99) and performed LSM analyses, finding the most robust association of word-level deficits (with PPT as a covariate) with damage to middle-posterior STG and STS.

Here we expand the number of subjects further and add several behavioral measures to directly compare our results to Mesulam et al. (2015), crucially including a measure of noncanonical sentence comprehension and CLSM analyses. We predicted that both word and noncanonical 
sentence comprehension would primarily involve damage to the middle-posterior temporal lobe and similar disconnection patterns throughout the temporal lobe. We expected a possible implication of parietal damage and/or disconnection in noncanonical sentence comprehension due to phonological working memory demands that are strongly associated with parietal areas (Buchsbaum et al., 2011; Buchsbaum \& D’Esposito, 2019; Hickok et al., 2003; Ravizza et al., 2004).

\section{Materials \& Methods}

\subsection{Subjects and measures}

We performed behavioral and lesion mapping analyses in four partially overlapping groups of English-speaking subjects (Table 1). Group 1 consisted of 218 subjects who were assessed on the Western Aphasia Battery-Revised (Kertesz, 2007), with subsets of this group being assessed on a variety of other measures. Group 2 consisted of a subset of 180 subjects who were assessed on the Pyramids and Palm Trees test (Howard \& Patterson, 1992). Group 3 consisted of a subset of 130 subjects who were assessed on one of two similar assessments of sentence comprehension ability involving picture-matching and a variety of semantically reversible canonical and noncanonical sentence structures, the Sentence Comprehension Test subset of the Northwestern Assessment of Verbs and Sentences (NAVS) (Cho-Reyes \& Thompson, 2012) $(\mathrm{N}=82)$ or a task which we label here the Icelandic Task (since its translation was first used in a sample of Icelandic stroke survivors with aphasia; Magnusdottir, 2005; Magnusdottir et al., 2013) $(\mathrm{N}=48)$. Finally, Group 4 consisted of a subset of 92 subjects who were evaluated for expressive agrammatism using consensus perceptual ratings of spontaneous speech samples in one of two studies, Den Ouden et al. (2019) ( $\mathrm{N}=39)$ or (Matchin, Basilakos, Stark, et al., 2020) $(\mathrm{N}=53)$. All of the lesion maps and behavioral data for subjects enrolled in this study are available for download at https://www.dropbox.com/sh/3w4aeizgypfs 7sd/AABW8Yn5qDUFeBj90WKsBqAa?dl=0 (use "wernickeConundrumRevisited_CLSM.xlsx" file).

All subjects were recruited through local advertisement. They provided informed consent to participate in this study, which was approved by the Institutional Review Boards at the University of South Carolina and the Medical University of South Carolina. All subjects were native speakers of American English and had at least one ischemic stroke to the left hemisphere at least six months prior to study inclusion.

\begin{tabular}{|l|l|l|l|l|}
\hline & Group 1 & Group 2 & Group 3 & Group 4 \\
\hline Measures & $\begin{array}{l}\text { Western } \\
\text { Aphasia } \\
\text { Battery-Revised }\end{array}$ & $\begin{array}{l}\text { Pyramids and } \\
\text { Palm Trees }\end{array}$ & $\begin{array}{l}\text { Noncanonical } \\
\text { Sentence } \\
\text { Comprehension }\end{array}$ & $\begin{array}{l}\text { Perceptual } \\
\text { Ratings of } \\
\text { Expressive } \\
\text { Agrammatism }\end{array}$ \\
\hline $\begin{array}{l}\text { Total number of } \\
\text { subjects }\end{array}$ & $\mathrm{N}=218$ & $\mathrm{~N}=180$ & $\begin{array}{l}\text { Total N = 130 } \\
\text { Icelandic task: } \\
\text { N = 48 } \\
\text { NAVS: } \mathrm{N}=82\end{array}$ & $\begin{array}{l}\text { Total N = 92 } \\
\text { Den Ouden et al. } \\
\text { (2019): } \mathrm{N}=39 \\
\text { Matchin et al. } \\
\text { (2020): } \mathrm{N}=53\end{array}$ \\
\hline
\end{tabular}




\begin{tabular}{|c|c|c|c|c|}
\hline Sex & $\begin{array}{l}133 \text { Male, } 85 \\
\text { Female }\end{array}$ & $\begin{array}{l}112 \text { male, } 68 \\
\text { female }\end{array}$ & $\begin{array}{l}83 \text { male, } 47 \\
\text { female }\end{array}$ & $\begin{array}{l}60 \text { male, } 32 \\
\text { female }\end{array}$ \\
\hline $\begin{array}{l}\text { Mean age at } \\
\text { testing (years) }\end{array}$ & $\begin{array}{l}60.3(\mathrm{SD}= \\
11.4)\end{array}$ & $60.5(\mathrm{SD}=11.4)$ & $\begin{array}{l}60.0(\mathrm{SD}= \\
10.7)\end{array}$ & $58.7(\mathrm{SD}=11.3)$ \\
\hline $\begin{array}{l}\text { Mean months } \\
\text { post-first stroke } \\
\text { at initial testing }\end{array}$ & $\begin{array}{l}42.6(\mathrm{SD}= \\
48.3)\end{array}$ & $41.2(\mathrm{SD}=47.6)$ & $\begin{array}{l}45.3(\mathrm{SD}= \\
50.4)\end{array}$ & $45.6(\mathrm{SD}=48.5)$ \\
\hline $\begin{array}{l}\text { Mean number } \\
\text { of strokes }\end{array}$ & $1.2(\mathrm{SD}=0.5)$ & $1.2(\mathrm{SD}=.5)$ & $1.2(\mathrm{SD}=0.5)$ & $1.1(\mathrm{SD}=0.4)$ \\
\hline $\begin{array}{l}\text { Mean education } \\
\text { (years) }\end{array}$ & $\begin{array}{l}15.0(\mathrm{SD}=2.3) \\
* \mathrm{~N}=210\end{array}$ & $\begin{array}{l}15.0(\mathrm{SD}=2.3) \\
* \mathrm{~N}=175\end{array}$ & $\begin{array}{l}15.4(\mathrm{SD}= \\
2.4), * \mathrm{~N}=128\end{array}$ & $15.3(\mathrm{SD}=2.4)$ \\
\hline $\begin{array}{l}\text { Mean lesion } \\
\text { volume }\left(\mathrm{mm}^{3}\right)\end{array}$ & $\begin{array}{l}120,855(\mathrm{SD}= \\
97,488)\end{array}$ & $\begin{array}{l}128,446(\mathrm{SD}= \\
97,036)\end{array}$ & $\begin{array}{l}111,267(\mathrm{SD}= \\
92,645)\end{array}$ & $\begin{array}{l}96,175(\mathrm{SD}= \\
84,514)\end{array}$ \\
\hline $\begin{array}{l}\text { Mean WAB-R } \\
A Q\end{array}$ & $\begin{array}{l}61.4(\mathrm{SD}= \\
28.1)\end{array}$ & $60.0(\mathrm{SD}=26.6)$ & $\begin{array}{l}65.3(\mathrm{SD}= \\
26.9)\end{array}$ & $75.8(\mathrm{SD}=19.9)$ \\
\hline $\begin{array}{l}\text { Mean WAB-R } \\
\text { Auditory Word } \\
\text { Comprehension }\end{array}$ & $\begin{array}{l}50.0(\mathrm{SD}= \\
13.2)\end{array}$ & $49.8(\mathrm{SD}=12.9)$ & $\begin{array}{l}51.0(\mathrm{SD}= \\
12.7)\end{array}$ & $54.7(\mathrm{SD}=9.0)$ \\
\hline $\begin{array}{l}\text { Mean WAB-R } \\
\text { Sequential } \\
\text { Commands }\end{array}$ & $\begin{array}{l}51.4(\mathrm{SD}= \\
23.5)\end{array}$ & $50.4(\mathrm{SD}=22.5)$ & $\begin{array}{l}54.5(\mathrm{SD}= \\
22.7)\end{array}$ & $61.0(\mathrm{SD}=19.5)$ \\
\hline $\begin{array}{l}\text { Mean WAB-R } \\
\text { Repetition }\end{array}$ & $5.5(\mathrm{SD}=3.4)$ & $5.3(\mathrm{SD}=3.3)$ & $5.9(\mathrm{SD}=3.3)$ & $7.0(\mathrm{SD}=2.7)$ \\
\hline
\end{tabular}

Table 1. Subject information for the four partially overlapping groups of subjects. SD = standard deviation. AQ = aphasia quotient of the Western Aphasia Battery-Revised, a summary measure of overall language ability; WAB-R = Western Aphasia Battery-Revised; SD = standard deviation. * education information was not available for all subjects, the number for which education information was available is indicated.

In order to compare our study effectively with the studies of Mesulam et al. in PPA, (Mesulam et al., 2015, 2019) we included a similar set of six behavioral measures: the WAB-R Auditory Word Comprehension subtest, the Pyramids and Palm Trees Test, the Philadelphia Naming Test, noncanonical sentence comprehension, the WAB-R Repetition subtest, and our perceptual ratings of expressive agrammatism. Each of these measures is described below. Out of these six measures, we ultimately performed four lesion mapping analyses, described in section 2.3.

The Auditory Word Recognition subtest of the WAB-R (Kertesz, 2007) involves asking the subject to point to real-world objects or printed images as requested, given verbal instructions by the experimenter. Subjects are prompted on each of 60 items with a short sentence, e.g. "point to the _" or "show me the _." The test involves multiple types of tested words, including real household objects, pictured objects (the same as real objects), pictured shapes, pictured letters, pictured numbers, pictured colors, real world furniture, real world body parts, real world fingers, and real world body parts on the correct side. For each item the subject receives 1 point, for a total of 60 points. Importantly, the test does not require syntactic parsing in order to perform correctly, as the subject only needs to identify the lexical item presented in each item. 
The WAB-R repetition subtest (Kertesz, 2007) involves presenting a series of increasingly more complex utterances and requiring subjects to repeat them verbatim. Scoring is based on the number of words correctly recalled in the correct order.

The Pyramids and Palm Trees test (Howard \& Patterson, 1992) involves presenting a target picture with two candidate pictures below that are possible associates of the target picture (e.g., the target picture could be a pyramid, with candidate pictures of palm trees and pine trees). The subject is required to point to the candidate picture that is more related to the target picture (e.g. the palm trees). There are a total of 52 trials. This task was included in order to provide a control for object recognition and non-verbal semantic processing in the WAB-R word comprehension test (as in Mesulam et al., 2015 and Bonilha et al., 2017).

The Philadelphia Naming Test (PNT) (Roach et al., 1996) is a 175-item assessment of picture naming, involving the presentation of a number of simple line drawings. Here we used the total number of items correctly named on the task (rather than phonological or semantic errors).

Our Noncanonical Sentence Comprehension measure was derived from either the NAVS (N = $82)$ or the Icelandic task $(\mathrm{N}=48)$. The NAVS Sentence Comprehension Test (Cho-Reyes \& Thompson, 2012) involves testing the comprehension of a variety of canonical and noncanonical sentence types, each with five total trials, assessed via pointing to the correct picture. Mesulam et al. (2015) assessed the comprehension performance on the three noncanonical sentence types: passives (with a by-phrase) e.g. the dog is chased by the cat, object-extracted WH-questions, e.g. who is the cat chasing?, and object-relatives, e.g. Pete saw the boy who the girl is pulling, for a maximum score of 15. The Icelandic task includes a similar set of canonical and noncanonical sentence types, each with five total trials: passives (with a by-phrase), e.g. the boy is painted by the girl, object-extracted WH-questions, e.g. which boy is the girl painting?, and object clefts, e.g. it is the girl that the boy paints. The sentence types across the two tasks are not strictly identical, but involve essentially the same structures with the same degree of complexity, including the key factor of noncanonical object-first word order. Therefore, for subjects who were not assessed with the NAVS, we calculated the equivalent scores on the Icelandic task (correct noncanonical trials, out of 15 points).

The Expressive Agrammatism measure was a perceptual measure of grammatical deficits in speech production. We derived this measure from samples of connected speech production elicited either by describing the Cookie Theft picture $(\mathrm{N}=39$, Goodglass \& Kaplan, 1983, as reported in Den Ouden et al., 2019) or retelling the story of Cinderella in their own words (N 53, MacWhinney et al., 2011, as reported in Matchin et al., 2020). Production samples were rated independently by speech and language experts for the systematic simplification of sentence structure and omission of function words and morphemes. This resulted in a categorical assessment for each subject, either agrammatic or not.

\subsection{Brain imaging and lesion mapping}

We acquired anatomical MRI and DTI data using the same parameters and procedures as described in (Bonilha et al., 2017; D. Den Ouden et al., 2019; Fridriksson et al., 2018). Neuroimaging data were collected at the University of South Carolina and the Medical 
University of South Carolina. Lesions were demarcated onto each subject's T2 image by an expert technician or an expert neurologist blind to the behavioral data.

Lesion overlap maps for both groups are shown in Figure 1. Overall, there was good coverage in perisylvian cortex, covering all relevant language-related regions of interest in the JHU atlas (Faria et al., 2012) which we used for lesion-symptom mapping (LSM) and connectome-based lesion-symptom mapping (CLSM) analyses.

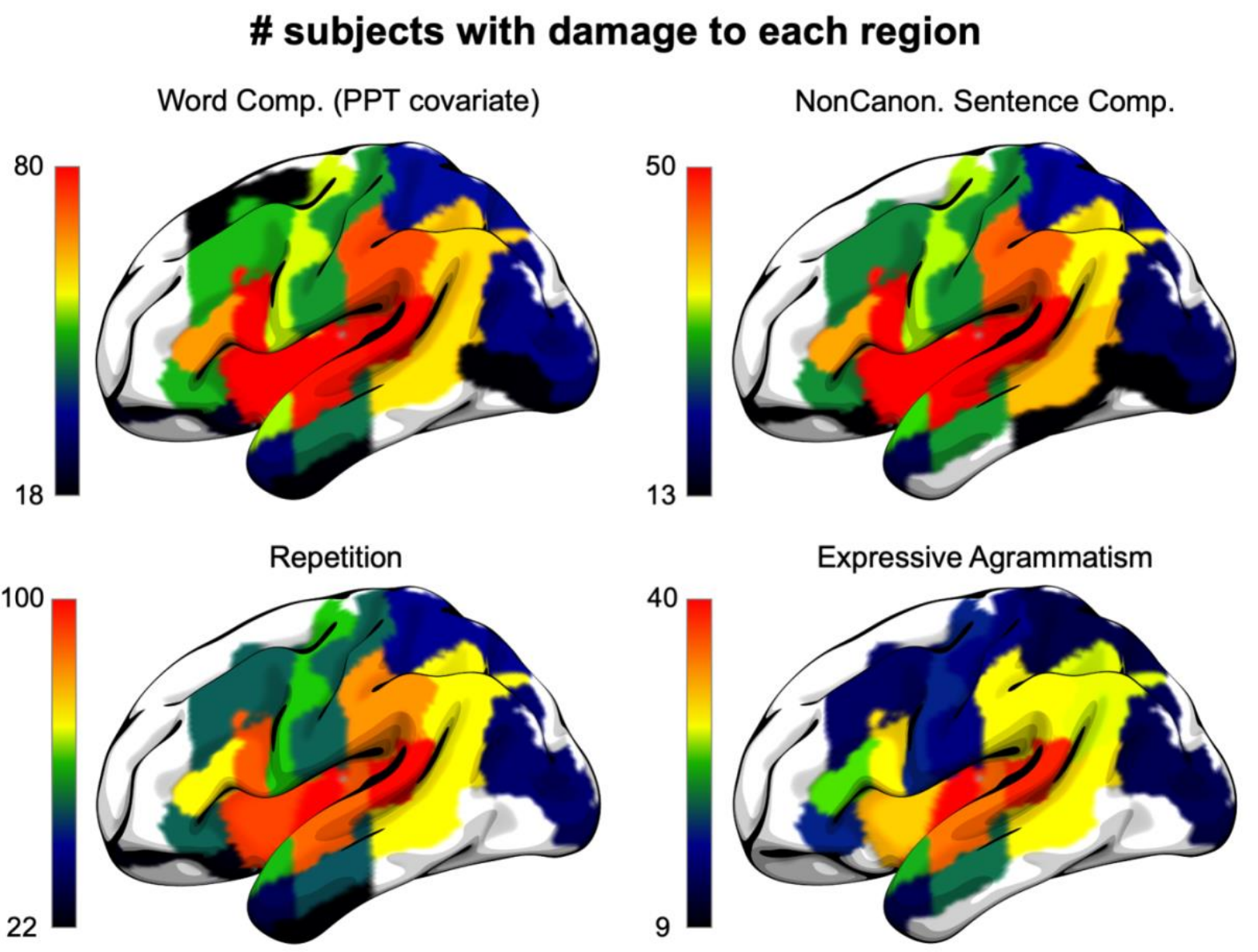

Figure 1. Lesion overlap maps for each group associated with the behavioral measures for which we analyzed lesion-deficit correlations. Note that the lower value in each color spectrum indicates the minimum number of subjects with damage to each region that was required for our $10 \%$ lesion load threshold.

\subsection{Analyses}

\subsubsection{Behavioral}

To examine the relationship among the behavioral variables, we performed non-parametric Spearman correlations using JASP (JASP Team, 2020). Missing data were accounted for with pairwise deletion. Non-parametric Spearman correlations were used given that the behavioral 
variables did not have pairwise normal distributions. Lesion volume is strongly correlated with aphasia severity in chronic stroke (Basso et al., 1980; Kertesz et al., 1979; Lahiri et al., 2021), including in our data (one-tailed Spearman's rho correlating WAB-R AQ and lesion volume = $0.694, \mathrm{p}=6.254 \times 10^{-33}$ ), and therefore a potential confound (DeMarco \& Turkeltaub, 2018; Ivanova et al., 2021), which we controlled by using lesion volume as a covariate in our LSM analyses. Similarly, we report behavioral correlations both with and without lesion volume as a covariate to evaluate overall severity effects. Mesulam et al. (2015) did not correct their behavioral correlation analyses for multiple comparisons, but given the large number of behavioral correlations we performed (15 pairwise correlations without lesion volume as a covariate, 15 pairwise correlations with lesion volume as a covariate), we report whether or not each correlation survived a Bonferroni correction for multiple comparisons, treating each set of 15 correlations (with and without the lesion volume covariate) as a separate family of tests, using an adjusted alpha level of $\mathrm{p}<0.003$.

\subsubsection{LSM}

With respect to LSM, using NiiStat (https://www.nitrc.org/projects/niistat/) we performed univariate regression analyses relating each behavioral variable to percent damage within each parcellated region (the number of voxels that were damaged divided by the total number of voxels in each region) contained within the JHU atlas (Faria et al., 2012) that had at least $10 \%$ of subjects with damage located there (Baldo et al., 2012; Ivanova et al., 2021). We corrected for multiple comparisons using permutation tests (10,000 permutations) and a corrected alpha threshold of $\mathrm{p}<0.05$ for each of the four behavioral measures we selected for maximum comparison to the results of Mesulam et al. (2015; 2019): WAB-R word comprehension with PPT as a covariate, noncanonical sentence comprehension, WAB-R repetition, and expressive agrammatism. Lesion volume was included as a covariate in all LSM analyses to ensure accurate localization (DeMarco \& Turkeltaub, 2018; Ivanova et al., 2021).

\subsubsection{CLSM}

For CLSM, we analyzed the diffusion-weighted images that were acquired for each subject and estimated the connection strength between a subset of 27 left hemisphere cortical regions within the JHU atlas (Faria et al., 2012) that included the entire lateral temporal cortex, inferior parietal lobe, inferior and middle frontal lobe, and lateral and medial visual cortex of the occipital lobe (a total of 351 distinct pairwise connections; each region included as a connection node is indicated by dots in Figure X, right). We estimated connection strength using fiber count (corrected for distance and region volume) for each of the 351 pairwise connections by using probabilistic tractography as implemented in FSL's FDT method (Behrens et al., 2007). For full details of the methodological approach, see other publications from our research group using the same method (Bonilha et al., 2017; Yourganov et al., 2016). We then performed regression analyses relating scores on each behavioral measure with the estimated connection strength for each connection using NiiStat (https://www.nitrc.org/projects/niistat/), correcting for multiple comparisons using permutation tests $(10,000$ permutations $)$ and a corrected alpha threshold of $\mathrm{p}<0.05$ for each of the four behavioral measures (WAB-R word comprehension with PPT as a covariate, noncanonical sentence comprehension, repetition, and expressive agrammatism). 
When including lesion volume as a covariate, we only identified 4 significant disconnections associated with noncanonical sentence comprehension deficits (all involving disconnection of occipital regions with either temporal pole or inferior temporal gyrus), and no significant disconnections associated with any of the other three behavioral measures we assessed (WAB-R word comprehension with PPT as a covariate; WAB-R repetition, and expressive agrammatism). It is as yet unclear whether lesion volume is critical for accurate localization as in LSM (DeMarco \& Turkeltaub, 2018; Ivanova et al., 2021). Therefore, we focus our results on analyses that did not include lesion volume as a covariate in our CLSM analyses, in line with previous reports from our research group (Bonilha et al., 2017; D. Den Ouden et al., 2019).

\section{Results}

\subsection{Behavioral}

Non-parametric Spearman correlations found significant correlations among most of our behavioral variables when lesion volume was not included as a covariate (Table 2). In fact, the only correlations that were not significant were between noncanonical sentence comprehension and PPT (although this nearly survived the Bonferroni correction for multiple comparisons), and between expressive agrammatism and three measures: noncanonical sentence comprehension, WAB-R repetition, and PPT. When lesion volume was included as a covariate, we found overall weaker correlations among the behavioral measures, and expressive agrammatism was no longer significantly correlated with any of the other measures (Table 3).

Similar to Mesulam et al. (2015), we found that WAB-R word comprehension and PPT scores were strongly correlated, justifying our use of PPT scores as a covariate in word comprehension to remove variance due to object recognition and non-verbal semantic processing in our lesionsymptom mapping analyses. We also found that noncanonical sentence comprehension and repetition scores were correlated, suggesting that at least some of the variance in sentence comprehension scores could be due to phonological working memory abilities.

There were notable differences from the behavioral correlations reported by (Mesulam et al., 2015). Importantly, we found robust correlations between noncanonical sentence comprehension and WAB-R word comprehension, whether or not lesion volume was included as a covariate, unlike Mesulam et al., who found that these variables were not correlated. This supports the classic view in stroke-based aphasia that word and sentence comprehension deficits coincide with similar patterns of damage to Wernicke's area. We also found that WAB-R repetition was very robustly correlated with WAB-R word comprehension, whereas Mesulam et al. found that word comprehension and repetition were not correlated.

Finally, we also found that noncanonical sentence comprehension was not correlated with expressive agrammatism, whether or not lesion volume was included as a covariate. Although correlations between expressive agrammatism and other behavioral variables were not assessed in Mesulam et al., (2015) or (2019), this lack of a relationship in our data speaks against one of the major ideas promoted by Mesulam et al. (2015). Namely, they suggested that sentence comprehension deficits in both PPA and stroke-based aphasia are due to degeneration and/or disconnection of a frontal-based grammatical processing center that affects both production and 
comprehension. Under this perspective, one would expect that both expressive agrammatism and noncanonical sentence comprehension would be correlated, but they were not. Note that we did find that expressive agrammatism correlated with WAB-R word comprehension and picture naming when lesion volume was not included as a covariate; thus the failure to identify a correlation between expressive agrammatism and noncanonical sentence comprehension cannot be merely due to a lack of statistical power.

\begin{tabular}{|c|c|c|c|c|c|}
\hline & $\begin{array}{l}\text { Philadelphia } \\
\text { Naming Task }\end{array}$ & $\begin{array}{l}\text { Noncanonical } \\
\text { Sentence } \\
\text { Comprehension }\end{array}$ & $\begin{array}{l}\text { WAB-R } \\
\text { Repetition }\end{array}$ & $\begin{array}{l}\text { Pyramids } \\
\text { and Palm } \\
\text { Trees }\end{array}$ & $\begin{array}{l}\text { Expressive } \\
\text { Agrammatism }\end{array}$ \\
\hline $\begin{array}{l}\text { WAB-R Word } \\
\text { Comprehension }\end{array}$ & $\begin{array}{l}\mathrm{N}=162 \\
\text { rho }=0.565 \\
\mathbf{p}<\mathbf{0 . 0 0 1}\end{array}$ & $\begin{array}{l}\mathrm{N}=130 \\
\text { rho }=0.415, \mathbf{p} \\
<\mathbf{0 . 0 0 1}\end{array}$ & $\begin{array}{l}\mathrm{N}=218 \\
\text { rho }=0.738 \\
\mathbf{p}<\mathbf{0 . 0 0 1}\end{array}$ & $\begin{array}{l}\mathrm{N}=181 \\
\text { rho }= \\
0.622, \mathbf{p}< \\
\mathbf{0 . 0 0 1}\end{array}$ & $\begin{array}{l}\mathrm{N}=92 \\
\text { rho }=0.377, \mathbf{p} \\
<\mathbf{0 . 0 0 1}\end{array}$ \\
\hline $\begin{array}{l}\text { Philadelphia } \\
\text { Naming Task }\end{array}$ & & $\begin{array}{l}\mathrm{N}=102 \\
\text { rho }=0.451, \mathbf{p} \\
<\mathbf{0 . 0 0 1}\end{array}$ & $\begin{array}{l}\mathrm{N}=162 \\
\text { rho }=0.802 \\
\mathbf{p}<\mathbf{0 . 0 0 1}\end{array}$ & $\begin{array}{l}\mathrm{N}=155 \\
\text { rho }= \\
0.408, \mathbf{p}< \\
\mathbf{0 . 0 0 1}\end{array}$ & $\begin{array}{l}\mathrm{N}=73 \\
\text { rho }=0.350 \\
\mathbf{p}<\mathbf{0 . 0 0 1}\end{array}$ \\
\hline $\begin{array}{l}\text { Noncanonical } \\
\text { Sentence } \\
\text { Comprehension }\end{array}$ & & & $\begin{array}{l}\mathrm{N}=130 \\
\text { rho }=0.441 \\
\mathbf{p}<\mathbf{0 . 0 0 1}\end{array}$ & $\begin{array}{l}\mathrm{N}=108 \\
\text { rho }= \\
0.236, p= \\
0.007\end{array}$ & $\begin{array}{l}\mathrm{N}=79 \\
\text { rho }=0.101 \\
\mathrm{p}=0.197\end{array}$ \\
\hline $\begin{array}{l}\text { WAB-R } \\
\text { Repetition }\end{array}$ & & & & $\begin{array}{l}\mathrm{N}=181 \\
\text { rho }= \\
0.502, \mathbf{p}< \\
\mathbf{0 . 0 0 1}\end{array}$ & $\begin{array}{l}\mathrm{N}=92 \\
\text { rho }=0.205 \\
\mathrm{p}=0.039\end{array}$ \\
\hline $\begin{array}{l}\text { Pyramids and } \\
\text { Palm Trees }\end{array}$ & & & & & $\begin{array}{l}\mathrm{N}=75 \\
\text { rho }=0.112 \\
\mathrm{p}=0.164\end{array}$ \\
\hline
\end{tabular}

Table 2. Non-parametric Spearman correlations among behavioral measures without lesion volume as a covariate. Correlation anlayses that survived the Bonferroni correction for multiple comparisons using an adjusted alpha of $\mathrm{p}<0.003$ are indicated in bold.

\begin{tabular}{|c|c|c|c|c|c|}
\hline & $\begin{array}{l}\text { Philadelphia } \\
\text { Naming } \\
\text { Task }\end{array}$ & $\begin{array}{l}\text { Noncanonical } \\
\text { Sentence } \\
\text { Comprehensi } \\
\text { on }\end{array}$ & $\begin{array}{l}\text { WAB-R } \\
\text { Repetition }\end{array}$ & $\begin{array}{l}\text { Pyramids } \\
\text { and Palm } \\
\text { Trees }\end{array}$ & $\begin{array}{l}\text { Expressive } \\
\text { Agrammatism }\end{array}$ \\
\hline $\begin{array}{l}\text { WAB-R Word } \\
\text { Comprehension }\end{array}$ & $\begin{array}{l}\mathrm{N}=162 \\
\text { rho }=0.433 \\
\mathbf{p}<\mathbf{0 . 0 0 1}\end{array}$ & $\begin{array}{l}\mathrm{N}=130 \\
\text { rho }=0.281 \\
\mathbf{p}<\mathbf{0 . 0 0 1}\end{array}$ & $\begin{array}{l}\mathrm{N}=218 \\
\text { rho }=0.549 \\
\mathbf{p}<\mathbf{0 . 0 0 1}\end{array}$ & $\begin{array}{l}\mathrm{N}=181 \\
\text { rho }=0.523 \\
\mathbf{p}<\mathbf{0 . 0 0 1}\end{array}$ & $\begin{array}{l}\mathrm{N}=92 \\
\text { rho }=0.038 \\
\mathrm{p}=0.359\end{array}$ \\
\hline $\begin{array}{l}\text { Philadelphia } \\
\text { Naming Task }\end{array}$ & & $\begin{array}{l}\mathrm{N}=103 \\
\text { rho }=0.364 \\
\mathbf{p}<\mathbf{0 . 0 0 1}\end{array}$ & $\begin{array}{l}\mathrm{N}=162 \\
\text { rho }=0.756 \\
\mathbf{p}<\mathbf{0 . 0 0 1}\end{array}$ & $\begin{array}{l}\mathrm{N}=155 \\
\text { rho }=0.306 \\
\mathbf{p}<\mathbf{0 . 0 0 1}\end{array}$ & $\begin{array}{l}\mathrm{N}=73 \\
\text { rho }=-0.051 \\
\mathrm{p}=0.683\end{array}$ \\
\hline $\begin{array}{l}\text { Noncanonical } \\
\text { Sentence } \\
\text { Comprehension }\end{array}$ & & & $\begin{array}{l}\mathrm{N}=130 \\
\text { rho }=0.317 \\
\mathbf{p}<\mathbf{0 . 0 0 1}\end{array}$ & $\begin{array}{l}\mathrm{N}=108 \\
\text { rho }=0.146 \\
\mathrm{p}=0.067\end{array}$ & $\begin{array}{l}\mathrm{N}=79 \\
\text { rho }=-0.137 \\
\mathrm{p}=0.875\end{array}$ \\
\hline
\end{tabular}




\begin{tabular}{|l|l|l|l|l|}
\hline $\begin{array}{l}\text { WAB-R } \\
\text { Repetition }\end{array}$ & & & $\begin{array}{l}\mathrm{N}=181 \\
\text { rho=0.359, } \\
\mathbf{p}<\mathbf{0 . 0 0 1}\end{array}$ & $\begin{array}{l}\mathrm{N}=92 \\
\text { rho=0.121, } \\
\mathrm{p}=0.152\end{array}$ \\
\hline $\begin{array}{l}\text { Pyramids and } \\
\text { Palm Trees }\end{array}$ & & & & $\begin{array}{l}\mathrm{N}=75 \\
\text { rho }=-0.076, \\
\mathrm{p}=0.747\end{array}$ \\
\hline
\end{tabular}

Table 3. Non-parametric Spearman correlations among behavioral measures including lesion volume as a covariate. Correlation analyses that survived the Bonferroni correction for multiple comparisons using an adjusted alpha of $\mathrm{p}<0.003$ are indicated in bold.

\section{$3.2 L S M$}

Univariate ROI-based LSM results are shown in Table 4 and Figure 2, left. WAB-R word comprehension deficits, with PPT scores as a covariate, were associated with damage to middle and posterior STG and MTG. Noncanonical sentence comprehension deficits were associated with damage to the same set of regions, although there were some differences in the strength of this effect across regions. This is consistent with the classic picture from stroke-based aphasia in which word and sentence comprehension coincide in Wernicke's aphasia following damage to posterior temporal lobe. By contrast, WAB-R repetition deficits were associated with damage to posterior STG, posterior insula, and superior longitudinal/arcuate fasciculus. Finally, expressive agrammatism was associated with damage to posterior middle frontal gyrus (MFG).

\begin{tabular}{|l|c|c|c|c|}
\hline & $\begin{array}{c}\text { WAB-R Word } \\
\text { Comprehension } \\
\text { with PPT } \\
\text { covariate }\end{array}$ & $\begin{array}{c}\text { Noncanonical } \\
\text { Sentence } \\
\text { Comprehension }\end{array}$ & $\begin{array}{c}\text { WAB-R } \\
\text { Repetition }\end{array}$ & $\begin{array}{c}\text { Expressive } \\
\text { Agrammatism }\end{array}$ \\
\hline STG & 4.18 & 4.36 & - & - \\
\hline MTG & 3.60 & 4.10 & - & - \\
\hline Posterior STG & 3.89 & 4.08 & 4.11 & - \\
\hline Posterior MTG & 4.88 & 3.75 & - & - \\
\hline Posterior insula & - & - & 3.35 & - \\
\hline $\begin{array}{l}\text { Superior } \\
\text { longitudinal/arcuate } \\
\text { fasciculus }\end{array}$ & - & - & 5.70 & 4.07 \\
\hline Posterior MFG & - & - & - & \\
\hline
\end{tabular}

Table 4. Significant regions from the JHU atlas (Faria et al., 2012) to which damage was associated with each of the four behavioral measures, with a permutation correction for multiple comparisons $(10,000$ permutations, corrected $\mathrm{p}<0.05)$. Values indicate $\mathrm{z}$-values. $\mathrm{MFG}=$ middle frontal gyrus; $\mathrm{MTG}=$ middle temporal gyrus; $\mathrm{STG}=$ superior temporal gyrus.

\subsection{CLSM}

CLSM results are shown in Table 5 and Figure 2, right. Both impaired WAB-R word comprehension (with PPT as a covariate) and noncanonical sentence comprehension were associated with a number of disconnections within the temporal lobe and between temporal and occipital areas. However, impaired noncanonical sentence comprehension was associated with 
additional disconnections between the parietal lobe (superior parietal gyrus, supramarginal gyrus, postcentral gyrus) and the temporal pole, as well as two frontal-occipital disconnections (IFG pars orbitalis and lateral fronto-orbital gyrus with the Cuneus). There were no frontal-temporal disconnections associated with either word or sentence comprehension deficits, and no disconnections involving Broca's area (pars triangularis and pars opercularis) or middle frontal gyrus. This speaks against the hypothesis of (Mesulam et al., 2015) that impaired noncanonical sentence comprehension in stroke-based aphasia results from impaired disconnection of a frontal-based grammatical processing system.

By contrast, impaired WAB-R repetition was associated with a very large number of significant disconnections, within the frontal and temporal lobes as well as between frontal lobe and all other lobes, and between temporal lobe and all other lobes (there were no significant disconnections between parietal and occipital lobes). Expressive agrammatism was associated primarily with significant disconnections within the frontal lobe, although there was one significant frontal-temporal disconnection (between gyrus rectus and superior temporal gyrus). These results underscore that the lack of significant frontal-temporal disconnections for noncanonical sentence comprehension was not due to lack of statistical power or other methodological issues.

\begin{tabular}{|c|c|c|}
\hline Measure & Connection & Z-score \\
\hline $\begin{array}{c}\text { WAB- } R \text { Word Comprehension } \\
\text { with PPT covariate }\end{array}$ & ITG $\leftrightarrow$ LG & 4.38 \\
\hline & ITG $\leftrightarrow$ Cuneus & 4.32 \\
\hline & MTG $\leftrightarrow$ SOG & 4.04 \\
\hline & MTG pole $\leftrightarrow$ SOG & 3.98 \\
\hline & ITG $\leftrightarrow$ SOG & 3.93 \\
\hline & MTG pole $\leftrightarrow$ posterior MTG & 3.80 \\
\hline & MTG pole $\leftrightarrow$ LG & 3.79 \\
\hline & ITG $\leftrightarrow$ posterior MTG & 3.72 \\
\hline & MTG $\leftrightarrow$ posterior MTG & 3.71 \\
\hline & MTG pole $\leftrightarrow$ Cuneus & 3.53 \\
\hline Noncanonical Sentence & ITG $\leftrightarrow$ Cuneus & 4.33 \\
\hline Comprehension & ITG $\leftrightarrow$ SOG & 4.31 \\
\hline & MTG $\leftrightarrow$ ITG & 4.08 \\
\hline & MTG pole $\leftrightarrow$ SOG & 3.93 \\
\hline & STG $\leftrightarrow$ SOG & 3.91 \\
\hline & STG pole $\leftrightarrow$ SOG & 3.88 \\
\hline & SPG $\leftrightarrow$ STG pole & 3.87 \\
\hline & SPG $\leftrightarrow$ MTG pole & 3.82 \\
\hline & STG $\leftrightarrow$ posterior STG & 3.75 \\
\hline & ITG $\leftrightarrow$ posterior MTG & 3.72 \\
\hline & IFG opercularis $\leftrightarrow$ IFG triangularis & 4.97 \\
\hline
\end{tabular}




\begin{tabular}{|c|c|c|}
\hline & IFG opercularis $\leftrightarrow$ PrCG & 4.94 \\
\hline & SMG $\leftrightarrow$ AG & 4.89 \\
\hline & PoCG $\leftrightarrow$ posterior MTG & 4.71 \\
\hline & IFG orbitalis $\leftrightarrow$ STG & 4.71 \\
\hline & IFG triangularis $\leftrightarrow$ STG & 4.68 \\
\hline & MTG $\leftrightarrow$ ITG & 4.58 \\
\hline & PrCG $\leftrightarrow$ posterior STG & 4.50 \\
\hline & IFG triangularis $\leftrightarrow$ PoCG & 4.42 \\
\hline Expressive Agrammatism & PoCG $\leftrightarrow$ AG & 4.35 \\
\hline & & 3.57 \\
\hline & IFG opercularis $\leftrightarrow$ IFG triangularis & 2.89 \\
\hline & IFG opercularis $\leftrightarrow$ PrCG & 2.81 \\
\hline & MFG $\leftrightarrow$ IFG triangularis & 2.71 \\
\hline & IFG orbitalis $\leftrightarrow$ IFG triangularis & 2.70 \\
\hline & posterior MFG $\leftrightarrow$ PrCG & 2.55 \\
\hline
\end{tabular}

Table 5. Top ten significant connections between regions from the JHU atlas (Faria et al., 2012) to which damage was associated with each of the four behavioral measures, with a permutation correction for multiple comparisons $(10,000$ permutations, corrected $\mathrm{p}<0.05)$. Values indicate $\mathrm{z}$ values. $\mathrm{AG}=$ angular gyrus; $\mathrm{IFG}=$ inferior frontal gyrus; $\mathrm{ITG}=$ inferior temporal gyrus; $\mathrm{LG}=$ lingual gyrus; $\mathrm{MTG}=$ middle temporal gyrus; $\mathrm{PoCG}=$ postcentral gyrus; $\mathrm{PrCG}=$ precentral gyrus; $\mathrm{RG}=$ gyrus rectus; $\mathrm{SMG}=$ supramarginal gyrus; $\mathrm{SOG}=$ superior occipital gyrus; $\mathrm{SPG}=$ superior parietal gyrus; STG = superior temporal gyrus. 

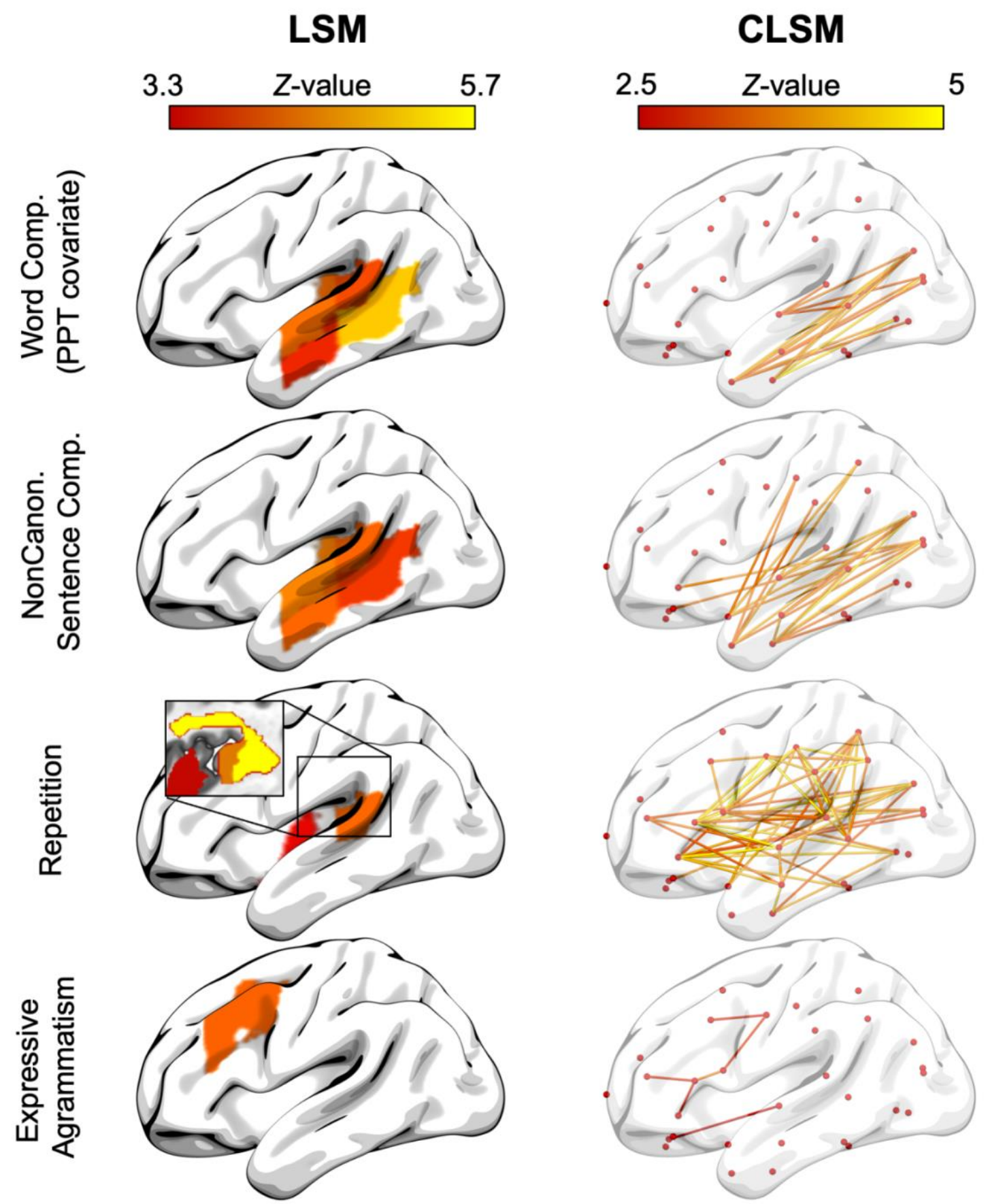

Figure 2. ROI-based lesion-symptom mapping (LSM) and connectome-based lesion-symptom mapping (CLSM) analyses. LEFT: LSM analyses within the JHU atlas ROIs (Faria et al., 2012) for each behavioral measure (incorporating lesion volume as a covariate), with a permutation correction for multiple comparisons $(10,000$ permutations, corrected $\mathrm{p}<0.05)$. RIGHT: CLSM analyses for each behavioral measure, the significant connections between ROIs based on the JHU atlas (Faria et al., 2012) ascertained by diffusion tensor imaging, with a permutation correction for multiple comparisons $(10,000$ permutations, corrected $\mathrm{p}<0.05)$. Red dots indicate the 30 nodes included in the CLSM analyses based on the JHU atlas. NonCanon. = noncanonical, comp. $=$ comprehension. 


\section{Discussion}

Consistent with previous research, the lesion correlates of word and sentence comprehension deficits in chronic post-stroke aphasia converged on the middle and posterior temporal lobe in our lesion symptom mapping (LSM) analyses. One of the main claims of Mesulam et al. (2015) is that damage to these areas, roughly the territory associated with Wernicke's area, involves "double disconnection" in Wernicke's aphasia. That is, they posited that word comprehension deficits follow from disconnection between superior temporal cortex and the anterior temporal lobe (ATL), and sentence comprehension deficits follow from disconnection between superior temporal cortex and frontal cortex. However, while our connectome-based lesion-symptom mapping (CLSM) analyses found that there were significant disconnections involving the temporal pole for both word and noncanonical sentence comprehension deficits, there were no frontal-temporal or frontal-parietal disconnections involved in either. There was also no significant behavioral correlation between noncanonical sentence comprehension and expressive agrammatism, while there was a significant behavioral correlation between noncanonical sentence comprehension and word comprehension. Thus, the fundamental prediction of Mesulam et al. (2015) that sentence comprehension deficits are caused by a frontal disconnection pattern, and that word and sentence comprehension deficits dissociate, was disconfirmed. Note that our results are unlikely to be due to lack of statistical power, as we identified significant frontaltemporal disconnections associated with speech repetition deficits, and a significant VLSM effect of expressive agrammatism in posterior MFG, with significantly damaged connections involving IFG and adjacent frontal regions.

The Mesulam et al. frontal-temporal disconnection proposal has logical force if a primary cortical locus of syntactic comprehension were in the frontal lobe, as suggested by many authors (Friederici, 2017; Grodzinsky et al., 2021; Hagoort, 2019; Tyler \& Marslen-Wilson, 2008; Ullman, 2016). Accordingly, we did find that agrammatic production deficits are associated with damage to the frontal lobe, including Broca's area, consistent with previous work (D. Den Ouden et al., 2019; Fridriksson et al., 2015; Matchin, Basilakos, Stark, et al., 2020; Mesulam, 2013; Sapolsky et al., 2010; Wilson, Henry, et al., 2010; Wilson, Dronkers, et al., 2010; Wilson et al., 2011). However, recent theories propose that the systems for building hierarchical syntactic structure in comprehension are in the posterior temporal lobe, and not the frontal lobe (Bornkessel-Schlesewsky \& Schlesewsky, 2013; Matchin \& Hickok, 2020). The lack of a significant association between noncanonical sentence comprehension deficits and damage to the inferior or middle frontal lobe, and the lack of an association with significant frontal-temporal disconnections, strongly speaks against the view that syntactic computations associated with sentence comprehension are processed in or around Broca's area and instead support the hypothesis that syntactic comprehension critically recruits posterior temporal cortex instead. Matchin and Hickok (2020) also proposed that the neural correlates for hierarchical syntax and lexical access are in the same region, intimately intertwined, which is consistent with modern approaches to syntax positing "lexicalized" syntactic representations. Under this view, coincidence of the lesion correlates of lexical and syntactic processing in the posterior temporal lobe is expected. 
Importantly, our analyses of noncanonical sentence comprehension were matched to Mesulam et al., (2015) in assessing overall comprehension ability. Previous studies from our group in strokebased aphasia that have examined residual performance on noncanonical structures after controlling for performance to canonical structures have associated deficits with damage to frontal regions (Fridriksson et al., 2018; Kristinsson et al., 2020, but see Matchin, Basilakos, den Ouden, et al., 2020 and Rogalsky et al., 2018 for conflicting results), or no association with damage to frontal regions, but disconnection (D. Den Ouden et al., 2019). Residual performance on noncanonical sentence comprehension after controlling for canonical sentence comprehension likely strongly highlights executive function resources that are necessary for processing particularly complex structures and revising sentence interpretation (Caplan \& Waters, 2013; Gibson, 1998; Just \& Carpenter, 1992; Lewis et al., 2006; Miller \& Chomsky, 1963; Novick et al., 2005; Rogalsky et al., 2008), thus some implication of frontal regions that are associated with these supporting mechanisms is expected (Kaan \& Swaab, 2002; Matchin, 2018; Matchin \& Hickok, 2020; Rogalsky \& Hickok, 2011; Stowe et al., 2005).

One prediction of Mesulam et al. (2015) was partially confirmed: auditory word comprehension deficits involve disconnection of the ATL. The disconnections we found were not unique to word comprehension deficits, as similar disconnections were associated with noncanonical sentence comprehension deficits. However, we note that the three primary disconnections that were identified in the word comprehension analysis involved the inferior temporal and middle temporal gyrus (consistent with the previous results from our group in 43 subjects reported by Bonilha et al., 2017), regions not included within the standard territory of the ATL. This suggests that the ATL may play a role in retrieving conceptual-semantic representations which are necessary to perform a picture task in some contexts, and thus ATL disconnection contributes in a minor way to the impaired word comprehension performance seen in many patients with poststroke aphasia involving damage to the posterior temporal lobe.

Under Mesulam et al.'s (2015; 2019) hypothesis, Wernicke's area (broadly construed) plays a key role in phonological short-term/working memory, which is in line with their reported association between repetition deficits and posterior temporal cortical degeneration (Mesulam et al., 2019). Consistent with this, in our study, repetition deficits were associated with arcuate fasciculus and posterior temporal damage and multiple frontal-parietal-temporal disconnections. Furthermore, deficits in noncanonical sentence comprehension (but not auditory word comprehension), were associated with significant disconnections of the parietal and temporal lobe. This converges with previous reports of associations between deficits in complex sentence comprehension and inferior parietal lobe damage in chronic stroke patients with aphasia (D. Den Ouden et al., 2019; Dronkers et al., 2004; Kristinsson et al., 2020; Magnusdottir et al., 2013; Pettigrew \& Hillis, 2014; Pillay et al., 2017; Rogalsky et al., 2018; Thothathiri et al., 2012), as well as functional neuroimaging studies finding activation for sensory-motor integration in this vicinity (Buchsbaum et al., 2001, 2011; Hickok et al., 2003). It is possible that these disconnections reflect the additional phonological short term memory resources that are useful in parsing sentence structure that are not typically required for word comprehension (Baddeley et al., 1981; Caplan \& Waters, 1999; Caspari et al., 1998, 1998; Gibson, 1998; Just \& Carpenter, 1992; Lewis et al., 2006; Miller \& Chomsky, 1963), which may explain why the significant correlation between word and sentence comprehension abilities was only moderate in strength. There were two frontal disconnections associated with deficits in noncanonical sentence 
comprehension (IFG orbitalis and lateral frontal-orbital gyrus), but neither of these regions are traditionally associated with grammatical processing, and both involved a disconnection with the cuneus (a part of early visual cortex) and not the temporal lobe.

Under our account, in which the middle-posterior temporal lobe plays a dominant causal role in both lexical access and syntactic comprehension, one would expect a strong association between word and sentence comprehension deficits and degeneration of the middle and posterior temporal lobe in PPA. However, this is not what is seen, as patients with the logopenic variant of PPA and posterior temporal-parietal degeneration do not typically show notable word comprehension deficits (Gorno-Tempini et al., 2004, 2008; Mesulam et al., 2015; Rohrer et al., 2013; but see Bonner \& Grossman, 2012). Also, Mesulam et al. (2015) do not report a notable association of atrophy in middle-posterior temporal lobe with deficits in noncanonical sentence comprehension. Why not? Some of the present authors have previously suggested that logopenic PPA does not necessarily involve complete degeneration of posterior temporal-parietal cortex, and that remaining neurons may be sufficient to perform the basic phonological and lexical access functions (Hillis et al., 2017). Additionally, some models posit an important role for the right hemisphere in phonological processing and lexical access (Hickok \& Poeppel, 2000, 2004, 2007), which could sufficiently compensate for left hemisphere degeneration. This is consistent with recent demonstrations of small but significant word comprehension deficits in right hemisphere stroke (Rogalsky et al., 2020).

One area of agreement between Mesulam et al. and our data is that damage or degeneration of the ATL is not implicated in noncanonical sentence comprehension deficits. However, we did find significant disconnections of the temporal pole related to impaired noncanonical sentence comprehension deficits. This is consistent with previous reports implicating damage to anterior temporal lobe in grammatical processing deficits (Dronkers et al., 2004; Magnusdottir et al., 2013). Nevertheless, we suggest that the (relatively less common) implication of ATL damage or disconnection in sentence comprehension deficits likely reflects semantic rather than syntactic deficits (Binder, 2017; Matchin \& Hickok, 2020), which is consistent with functional neuroimaging data (Goucha \& Friederici, 2015; Matchin et al., 2017, 2019; Pallier et al., 2011; Pylkkänen, 2020).

Why is there such a strong correlation between word comprehension deficits and peak ATL atrophy in PPA? For one, PPA is a progressive neurodegenerative disease which evolves to ultimately affect a number of cognitive domains (Gorno-Tempini et al., 2011; Mesulam et al., 2014), and functional neuroimaging studies of people with the semantic variant of PPA have shown abnormal activation patterns and functional connectivity in regions outside the ATL (Battistella et al., 2019; Kielar et al., 2018; Mummery et al., 1999; Ranasinghe et al., 2017; Sonty et al., 2003, 2007; Wilson et al., 2009). This suggests that the neuropathology of semantic PPA is more widespread than what shows up in gross measures of grey matter atrophy and may affect a broader network (potentially including middle and posterior temporal cortex) that contributes to word comprehension impairments. Individuals with PPA show neural degeneration far beyond the areas of peak atrophy (as seen in the figures in Mesulam et al. 2015), as well as disrupted functional networks beyond the sites of major neural degeneration. Longitudinal MRI and word comprehension testing reveals that deterioration in auditory word comprehension over time in PPA is associated with within-individual atrophy over time in left middle temporal cortex, left 
angular gyrus, and right inferior and middle temporal cortex (Faria et al., 2014). Second, the word level comprehension deficits seen in stroke patients and svPPA might be qualitatively different. Word comprehension deficits in stroke may be much more commonly due to deficits in basic linguistic processing, i.e. at the phonological processing and lexical/lemma access levels, whereas word comprehension deficits in PPA may be largely due to deficits in accessing finegrained semantic features of words downstream from lexical access. These semantic features could be characteristics of word representations rather than amodal conceptual information, which may remain intact in svPPA (Mesulam et al., 2013). These may be more completely disrupted in semantic PPA due to the pattern of neurodegeneration than is seen with strokes impinging on this area, or in resections.

Additionally, it is worth noting that the word comprehension task used by Mesulam and colleagues $(2015 ; 2019)$ consists of moderately difficult items of the Peabody Picture Vocabulary Task (PPVT) (Dunn \& Dunn, 2007), which involve much more complex semantic inference than the task we used, the Auditory Word Comprehension subtest of the WAB-R (Kertesz, 2007). We prefer the WAB-R word comprehension test as a basic measure of phonological and lexical processing, as it limits semantic processing demands as well as not requiring fine-grained visual processing and object recognition by asking subjects to pick out real world objects on most trials. Future studies should examine the relationship between these word comprehension measures and the results obtained in lesion-symptom mapping analyses in both PPA and stroke-based aphasia.

Overall, our combined VLSM and CLSM results speak against the hypothesis of Mesulam et al. (2015) of a double disconnection syndrome underlying word and sentence/syntactic comprehension deficits in post-stroke aphasia. Rather, our results support the classical concept of Wernicke's area as directly supporting both word and sentence comprehension, although our results do suggest that anterior temporal lobe and inferior parietal networks bolster core linguistic processing through semantic and phonological working memory resources, respectively. The discrepancy between our results and those of Mesulam et al. from PPA might be explained by differences between language deficits in post-stroke aphasia versus PPA or differences in tests used to assess comprehension, as described above. Alternatively, the conclusions based on PPA might be unfounded, because they were based on regions of peak atrophy associated with errors, rather than considering other areas of degeneration or dysfunction that might be responsible for deficits. Irrespective of the account of the discrepant results, our data provide strong evidence for the major role of Wernicke's area in both word and sentence comprehension.

\section{Acknowledgments}

This research was supported by National Institute on Deafness and Other Communication Disorders grants P50 DC014664 and U01 DC011739 awarded to Julius Fridriksson, and grant R01 DC014021. We would also like to thank Alexandra Basilakos and Brielle C. Stark for assistant with rating of speech samples, Leigh Ann Spell, Allison Croxton, Anna Doyle, Michele Martin, Katie Murphy, and Sara Sayers for their assistance with data collection, and graduate student clinicians in the Aphasia Lab for transcribing and coding speech samples. 


\section{References}

Amici, S., Brambati, S. M., Wilkins, D. P., Ogar, J., Dronkers, N. L., Miller, B. L., \& GornoTempini, M. L. (2007). Anatomical Correlates of Sentence Comprehension and Verbal Working Memory in Neurodegenerative Disease. Journal of Neuroscience, 27(23), 62826290. https://doi.org/10.1523/JNEUROSCI.1331-07.2007

Baddeley, A., Eldridge, M., \& Lewis, V. (1981). The Role of Subvocalisation in Reading. The Quarterly Journal of Experimental Psychology Section A, 33(4), 439-454. https://doi.org/10.1080/14640748108400802

Baldo, J. V., \& Dronkers, N. F. (2007). Neural correlates of arithmetic and language comprehension: A common substrate? Neuropsychologia, 45(2), 229-235. https://doi.org/10.1016/j.neuropsychologia.2006.07.014

Baldo, J. V., Wilson, S. M., \& Dronkers, N. F. (2012). Uncovering the Neural Substrates of Language: A Voxel-Based Lesion-Symptom Mapping Approach. In M. Faust (Ed.), The Handbook of the Neuropsychology of Language (pp. 582-594). Wiley-Blackwell. https://doi.org/10.1002/9781118432501.ch28

Basso, A., Capitani, E., Laiacona, M., \& Luzzatti, C. (1980). Factors Influencing Type and Severity of Aphasia. Cortex, 16(4), 631-636. https://doi.org/10.1016/S00109452(80)80011-6

Battistella, G., Henry, M., Gesierich, B., Wilson, S. M., Borghesani, V., Shwe, W., Miller, Z., Deleon, J., Miller, B. L., Jovicich, J., Papinutto, N., Dronkers, N. F., Seeley, W. W., Mandelli, M. L., \& Gorno-Tempini, M. L. (2019). Differential intrinsic functional connectivity changes in semantic variant primary progressive aphasia. NeuroImage: Clinical, 22, 101797. https://doi.org/10.1016/j.nicl.2019.101797

Beaulieu, C. (2014). The Biological Basis of Diffusion Anisotropy. In Diffusion MRI (pp. 155183). Elsevier. https://doi.org/10.1016/B978-0-12-396460-1.00008-1

Behrens, T. E. J., Berg, H. J., Jbabdi, S., Rushworth, M. F. S., \& Woolrich, M. W. (2007). Probabilistic diffusion tractography with multiple fibre orientations: What can we gain? NeuroImage, 34(1), 144-155. https://doi.org/10.1016/j.neuroimage.2006.09.018

Binder, J. R. (2017). Current Controversies on Wernicke's Area and its Role in Language. Current Neurology and Neuroscience Reports, 17(8), 58. https://doi.org/10.1007/s11910017-0764-8

Bogen, J. E., \& Bogen, G. M. (1976). Wernicke's region-Where is it? Annals of the New York Academy of Sciences, 280(1 Origins and E), 834-843. https://doi.org/10.1111/j.17496632.1976.tb25546.x

Bonilha, L., Hillis, A. E., Hickok, G., den Ouden, D. B., Rorden, C., \& Fridriksson, J. (2017). Temporal lobe networks supporting the comprehension of spoken words. Brain, 140(9), 2370-2380. https://doi.org/10.1093/brain/awx169

Bonilha, L., Rorden, C., \& Fridriksson, J. (2014). Assessing the Clinical Effect of Residual Cortical Disconnection After Ischemic Strokes. Stroke, 45(4), 988-993. https://doi.org/10.1161/STROKEAHA.113.004137

Bonner, M. F., \& Grossman, M. (2012). Gray Matter Density of Auditory Association Cortex Relates to Knowledge of Sound Concepts in Primary Progressive Aphasia. Journal of Neuroscience, 32(23), 7986-7991. https://doi.org/10.1523/JNEUROSCI.6241-11.2012 
Bornkessel-Schlesewsky, I., \& Schlesewsky, M. (2013). Reconciling time, space and function: A new dorsal-ventral stream model of sentence comprehension. Brain and Language, 125(1), 60-76. https://doi.org/10.1016/j.bandl.2013.01.010

Buchsbaum, B. R., Baldo, J., Okada, K., Berman, K. F., Dronkers, N., D’Esposito, M., \& Hickok, G. (2011). Conduction aphasia, sensory-motor integration, and phonological short-term memory - An aggregate analysis of lesion and fMRI data. Brain and Language, 119(3), 119-128. https://doi.org/10.1016/j.bandl.2010.12.001

Buchsbaum, B. R., \& D'Esposito, M. (2019). A sensorimotor view of verbal working memory. Cortex, 112, 134-148. https://doi.org/10.1016/j.cortex.2018.11.010

Buchsbaum, B. R., Hickok, G., \& Humphries, C. (2001). Role of left posterior superior temporal gyrus in phonological processing for speech perception and production. Cognitive Science, 25(5), 663-678. https://doi.org/10.1207/s15516709cog2505_2

Caplan, D., \& Waters, G. (2013). Memory mechanisms supporting syntactic comprehension. Psychonomic Bulletin \& Review, 20(2), 243-268. https://doi.org/10.3758/s13423-0120369-9

Caplan, D., \& Waters, G. S. (1999). Verbal working memory and sentence comprehension. Behavioral and Brain Sciences, 22(01), 77-126. https://doi.org/10.1017/S0140525X99001788

Caspari, I., Parkinson, S. R., LaPointe, L. L., \& Katz, R. C. (1998). Working Memory and Aphasia. Brain and Cognition, 37(2), 205-223. https://doi.org/10.1006/brcg.1997.0970

Catani, M., \& Mesulam, M. (2008). The arcuate fasciculus and the disconnection theme in language and aphasia: History and current state. Cortex, 44(8), 953-961. https://doi.org/10.1016/j.cortex.2008.04.002

Cho-Reyes, S., \& Thompson, C. K. (2012). Verb and sentence production and comprehension in aphasia: Northwestern Assessment of Verbs and Sentences (NAVS). Aphasiology, 26(10), 1250-1277. https://doi.org/10.1080/02687038.2012.693584

Damasio, A. R. (1992). Aphasia. New England Journal of Medicine, 326(8), 531-539.

Del Gaizo, J., Fridriksson, J., Yourganov, G., Hillis, A. E., Hickok, G., Misic, B., Rorden, C., \& Bonilha, L. (2017). Mapping Language Networks Using the Structural and Dynamic Brain Connectomes. Eneuro, 4(5), ENEURO.0204-17.2017. https://doi.org/10.1523/ENEURO.0204-17.2017

DeMarco, A. T., \& Turkeltaub, P. E. (2018). A multivariate lesion symptom mapping toolbox and examination of lesion-volume biases and correction methods in lesion-symptom mapping. Human Brain Mapping, 39(11), 4169-4182. https://doi.org/10.1002/hbm.24289

Den Ouden, D., Malyutina, S., Basilakos, A., Bonilha, L., Gleichgerrcht, E., Yourganov, G., Hillis, A. E., Hickok, G., Rorden, C., \& Fridriksson, J. (2019). Cortical and structuralconnectivity damage correlated with impaired syntactic processing in aphasia. Human Brain Mapping, 40(7), 2153-2173. https://doi.org/10.1002/hbm.24514

Den Ouden, D.-B., Saur, D., Mader, W., Schelter, B., Lukic, S., Wali, E., Timmer, J., \& Thompson, C. K. (2012). Network modulation during complex syntactic processing. NeuroImage, 59(1), 815-823. https://doi.org/10.1016/j.neuroimage.2011.07.057

Dronkers, N. F., Wilkins, D. P., Van Valin, R. D., Redfern, B. B., \& Jaeger, J. J. (2004). Lesion analysis of the brain areas involved in language comprehension. Cognition, 92(1-2), 145-177. https://doi.org/10.1016/j.cognition.2003.11.002

Dunn, L., \& Dunn, L. (2007). Peabody picture vocabulary test-4. Pearson. 
Faria, A. V., Joel, S. E., Zhang, Y., Oishi, K., van Zjil, P. C. M., Miller, M. I., Pekar, J. J., \& Mori, S. (2012). Atlas-based analysis of resting-state functional connectivity: Evaluation for reproducibility and multi-modal anatomy-function correlation studies. NeuroImage, 61(3), 613-621. https://doi.org/10.1016/j.neuroimage.2012.03.078

Faria, A. V., Sebastian, R., Newhart, M., Mori, S., \& Hillis, A. E. (2014). Longitudinal imaging and deterioration in word comprehension in primary progressive aphasia: Potential clinical significance. Aphasiology, 28(8-9), 948-963. https://doi.org/10.1080/02687038.2014.911241

Fedorenko, E., Blank, I. A., Siegelman, M., \& Mineroff, Z. (2020). Lack of selectivity for syntax relative to word meanings throughout the language network. Cognition, 203, 104348. https://doi.org/10.1016/j.cognition.2020.104348

Fridriksson, J., Bonilha, L., \& Rorden, C. (2007). Severe Broca's Aphasia without Broca's Area Damage. Behavioural Neurology, 18(4), 237-238. https://doi.org/10.1155/2007/785280

Fridriksson, J., den Ouden, D.-B., Hillis, A. E., Hickok, G., Rorden, C., Basilakos, A., Yourganov, G., \& Bonilha, L. (2018). Anatomy of aphasia revisited. Brain, 141(3), 848862. https://doi.org/10.1093/brain/awx363

Fridriksson, J., Fillmore, P., Guo, D., \& Rorden, C. (2015). Chronic Broca's Aphasia Is Caused by Damage to Broca's and Wernicke's Areas. Cerebral Cortex, 25(12), 4689-4696. https://doi.org/10.1093/cercor/bhu152

Friederici, A. D. (2017). Language in our brain: The origins of a uniquely human capacity. MIT Press.

Geschwind, N. (1972). Language and the Brain. Scientific American, 226(4), 76-83.

Geschwind, N. (1979). Specializations of the Human Brain. Scientific American, 241(3), 180199. https://doi.org/10.1038/scientificamerican0979-180

Gibson, E. (1998). Linguistic complexity: Locality of syntactic dependencies. Cognition, 68(1), 1-76. https://doi.org/10.1016/S0010-0277(98)00034-1

Goodglass, H., \& Kaplan, E. (1983). Boston Diagnostic Aphasia Examination (BDAE) (2nd ed.). Lippincott Williams \& Wilkins.

Gorno-Tempini, M. L., Brambati, S. M., Ginex, V., Ogar, J., Dronkers, N. F., Marcone, A., Perani, D., Garibotto, V., Cappa, S. F., \& Miller, B. L. (2008). The logopenic/phonological variant of primary progressive aphasia. Neurology, 71(16), 12271234. https://doi.org/10.1212/01.wnl.0000320506.79811.da

Gorno-Tempini, M. L., Dronkers, N. F., Rankin, K. P., Ogar, J. M., Phengrasamy, L., Rosen, H. J., Johnson, J. K., Weiner, M. W., \& Miller, B. L. (2004). Cognition and anatomy in three variants of primary progressive aphasia. Annals of Neurology, 55(3), 335-346. https://doi.org/10.1002/ana.10825

Gorno-Tempini, M. L., Hillis, A. E., Weintraub, S., Kertesz, A., Mendez, M., Cappa, S. F., Ogar, J. M., Rohrer, J. D., Black, S., Boeve, B. F., Manes, F., Dronkers, N. F., Vandenberghe, R., Rascovsky, K., Patterson, K., Miller, B. L., Knopman, D. S., Hodges, J. R., Mesulam, M. M., \& Grossman, M. (2011). Classification of primary progressive aphasia and its variants. Neurology, 76(11), 1006-1014. https://doi.org/10.1212/WNL.0b013e31821103e6

Goucha, T., \& Friederici, A. D. (2015). The language skeleton after dissecting meaning: A functional segregation within Broca's Area. NeuroImage, 114, 294-302. https://doi.org/10.1016/j.neuroimage.2015.04.011 
Grodzinsky, Y., Pieperhoff, P., \& Thompson, C. (2021). Stable brain loci for the processing of complex syntax: A review of the current neuroimaging evidence. Cortex, 142, 252-271. https://doi.org/10.1016/j.cortex.2021.06.003

Hagoort, P. (2019). The neurobiology of language beyond single-word processing. Science, 366(6461), 55-58. https://doi.org/10.1126/science.aax0289

Hagoort, P., \& Indefrey, P. (2014). The Neurobiology of Language Beyond Single Words. Annual Review of Neuroscience, 37(1), 347-362. https://doi.org/10.1146/annurev-neuro071013-013847

Hickok, G., Buchsbaum, B., Humphries, C., \& Muftuler, T. (2003). Auditory-Motor Interaction Revealed by fMRI: Speech, Music, and Working Memory in Area Spt. Journal of Cognitive Neuroscience, 15(5), 10.

Hickok, G., \& Poeppel, D. (2000). Towards a functional neuroanatomy of speech perception. Trends in Cognitive Sciences, 4(4), 131-138. https://doi.org/10.1016/S13646613(00)01463-7

Hickok, G., \& Poeppel, D. (2004). Dorsal and ventral streams: A framework for understanding aspects of the functional anatomy of language. Cognition, 92(1-2), 67-99. https://doi.org/10.1016/j.cognition.2003.10.011

Hickok, G., \& Poeppel, D. (2007). The cortical organization of speech processing. Nature Reviews Neuroscience, 8(5), 393-402. https://doi.org/10.1038/nrn2113

Hillis, A. E. (2007). Aphasia: Progress in the last quarter of a century. Neurology, 69(2), 200213. https://doi.org/10.1212/01.wnl.0000265600.69385.6f

Hillis, A. E., Rorden, C., \& Fridriksson, J. (2017). Brain regions essential for word comprehension: Drawing inferences from patients: Lesion-Deficit Mapping. Annals of Neurology, 81(6), 759-768. https://doi.org/10.1002/ana.24941

Howard, D., \& Patterson, K. (1992). The pyramids and palm trees test: A test of semantic access from words and pictures. Harcourt Assessment.

Ivanova, M. V., Herron, T. J., Dronkers, N. F., \& Baldo, J. V. (2021). An empirical comparison of univariate versus multivariate methods for the analysis of brain-behavior mapping. Human Brain Mapping, 42, 1070-1101.

JASP Team. (2020). JASP (0.14.1) [Computer software].

Just, M. A., \& Carpenter, P. A. (1992). A capacity theory of comprehension: Individual differences in working memory. Psychological Review, 99(1), 122-149.

Kaan, E., \& Swaab, T. Y. (2002). The brain circuitry of syntactic comprehension. Trends in Cognitive Sciences, 6(8), 350-356. https://doi.org/10.1016/S1364-6613(02)01947-2

Kertesz, A. (2007). Western Aphasia Battery-Revised. Grune and Stratton.

Kertesz, A., Harlock, W., \& Coates, R. (1979). Computer tomographic localization, lesion size, and prognosis in aphasia and nonverbal impairment. Brain and Language, 8(1), 34-50. https://doi.org/10.1016/0093-934X(79)90038-5

Kielar, A., Deschamps, T., Jokel, R., \& Meltzer, J. A. (2018). Abnormal language-related oscillatory responses in primary progressive aphasia. NeuroImage: Clinical, 18, 560-574. https://doi.org/10.1016/j.nicl.2018.02.028

Kristinsson, S., Thors, H., Yourganov, G., Magnusdottir, S., Hjaltason, H., Stark, B. C., Basilakos, A., den Ouden, D.-B., Bonilha, L., Rorden, C., Hickok, G., Hillis, A., \& Fridriksson, J. (2020). Brain Damage Associated with Impaired Sentence Processing in Acute Aphasia. Journal of Cognitive Neuroscience, 32(2), 256-271. https://doi.org/10.1162/jocn_a_01478 
Lahiri, D., Dubey, S., Ardila, A., \& Ray, B. K. (2021). Factors affecting vascular aphasia severity. Aphasiology, 35(5), 633-641. https://doi.org/10.1080/02687038.2020.1712587

Lewis, R. L., Vasishth, S., \& Van Dyke, J. A. (2006). Computational principles of working memory in sentence comprehension. Trends in Cognitive Sciences, 10(10), 447-454. https://doi.org/10.1016/j.tics.2006.08.007

Lichtheim, L. (1885). On aphasia. Brain, 7, 433-484.

MacWhinney, B., Fromm, D., Forbes, M., \& Holland, A. (2011). AphasiaBank: Methods for studying discourse. Aphasiology, 25(11), 1286-1307. https://doi.org/10.1080/02687038.2011.589893

Magnusdottir, S. (2005). Setningafraeðipróf (Test of Syntax). Landspítali University Hospital.

Magnusdottir, S., Fillmore, P., den Ouden, D. B., Hjaltason, H., Rorden, C., Kjartansson, O., Bonilha, L., \& Fridriksson, J. (2013). Damage to left anterior temporal cortex predicts impairment of complex syntactic processing: A lesion-symptom mapping study: ATL Damage Impairs Complex Syntax Processing. Human Brain Mapping, 34(10), 27152723. https://doi.org/10.1002/hbm.22096

Matchin, W. (2018). A neuronal retuning hypothesis of sentence-specificity in Broca's area. Psychonomic Bulletin \& Review, 25(5), 1682-1694. https://doi.org/10.3758/s13423-0171377-6

Matchin, W., Basilakos, A., den Ouden, D.-B., Stark, B. C., Hickok, G., \& Fridriksson, J. (2020). Functional differentiation in the language network revealed by lesion-symptom mapping [Preprint]. Neuroscience. https://doi.org/10.1101/2020.07.17.209262

Matchin, W., Basilakos, A., Stark, B. C., den Ouden, D.-B., Fridriksson, J., \& Hickok, G. (2020). Agrammatism and paragrammatism: A cortical double dissociation revealed by lesionsymptom mapping. Neurobiology of Language, 1-47. https://doi.org/10.1162/nol_a_00010

Matchin, W., Brodbeck, C., Hammerly, C., \& Lau, E. (2019). The temporal dynamics of structure and content in sentence comprehension: Evidence from fMRI-constrained MEG. Human Brain Mapping, 40(2), 663-678. https://doi.org/10.1002/hbm.24403

Matchin, W., Hammerly, C., \& Lau, E. (2017). The role of the IFG and pSTS in syntactic prediction: Evidence from a parametric study of hierarchical structure in fMRI. Cortex, 88, 106-123. https://doi.org/10.1016/j.cortex.2016.12.010

Matchin, W., \& Hickok, G. (2020). The Cortical Organization of Syntax. Cerebral Cortex, 30(3), $1481-1498$.

Mesulam, M.-M. (2013). Primary progressive aphasia and the language network: The $2013 \mathrm{H}$. Houston Merritt Lecture. Neurology, 81(5), 456-462. https://doi.org/10.1212/WNL.0b013e31829d87df

Mesulam, M.-M., Rader, B. M., Sridhar, J., Nelson, M. J., Hyun, J., Rademaker, A., Geula, C., Bigio, E. H., Thompson, C. K., Gefen, T. D., Weintraub, S., \& Rogalski, E. J. (2019). Word comprehension in temporal cortex and Wernicke area: A PPA perspective. Neurology, 92(3), e224-e233. https://doi.org/10.1212/WNL.0000000000006788

Mesulam, M.-M., Rogalski, E. J., Wieneke, C., Hurley, R. S., Geula, C., Bigio, E. H., Thompson, C. K., \& Weintraub, S. (2014). Primary progressive aphasia and the evolving neurology of the language network. Nature Reviews Neurology, 10(10), 554-569. https://doi.org/10.1038/nrneurol.2014.159 
Mesulam, M.-M., Thompson, C. K., Weintraub, S., \& Rogalski, E. J. (2015). The Wernicke conundrum and the anatomy of language comprehension in primary progressive aphasia. Brain, 138(8), 2423-2437. https://doi.org/10.1093/brain/awv154

Mesulam, M.-M., Wieneke, C., Hurley, R., Rademaker, A., Thompson, C. K., Weintraub, S., \& Rogalski, E. J. (2013). Words and objects at the tip of the left temporal lobe in primary progressive aphasia. Brain, 136(2), 601-618. https://doi.org/10.1093/brain/aws336

Miller, G. A., \& Chomsky, N. (1963). Finitary Models of Language Users. In Handbook of Mathematical Psychology (Vol. 2, pp. 419-491). Wiley.

Mummery, C. J., Patterson, K., Wise, R. J. S., Vandenbergh, R., Price, C. J., \& Hodges, J. R. (1999). Disrupted temporal lobe connections in semantic dementia. Brain, 122(1), 61-73.

Novick, J. M., Trueswell, J. C., \& Thompson-Schill, S. L. (2005). Cognitive control and parsing: Reexamining the role of Broca's area in sentence comprehension. Cognitive, Affective, \& Behavioral Neuroscience, 5(3), 263-281. https://doi.org/10.3758/CABN.5.3.263

Pallier, C., Devauchelle, A.-D., \& Dehaene, S. (2011). Cortical representation of the constituent structure of sentences. Proceedings of the National Academy of Sciences, 108(6), 25222527. https://doi.org/10.1073/pnas.1018711108

Pettigrew, C., \& Hillis, A. E. (2014). Role for memory capacity in sentence comprehension: Evidence from acute stroke. Aphasiology, 28(10), 1258-1280. https://doi.org/10.1080/02687038.2014.919436

Pillay, S. B., Binder, J. R., Humphries, C., Gross, W. L., \& Book, D. S. (2017). Lesion localization of speech comprehension deficits in chronic aphasia. Neurology, 88(10), 970-975. https://doi.org/10.1212/WNL.0000000000003683

Pylkkänen, L. (2020). Neural basis of basic composition: What we have learned from the redboat studies and their extensions. Philosophical Transactions of the Royal Society B: Biological Sciences, 375(1791), 20190299. https://doi.org/10.1098/rstb.2019.0299

Race, D. S., Ochfeld, E., Leigh, R., \& Hillis, A. E. (2012). Lesion analysis of cortical regions associated with the comprehension of Nonreversible and Reversible yes/no questions. Neuropsychologia, 50(8), 1946-1953. https://doi.org/10.1016/j.neuropsychologia.2012.04.019

Ranasinghe, K. G., Hinkley, L. B., Beagle, A. J., Mizuiri, D., Honma, S. M., Welch, A. E., Hubbard, I., Mandelli, M. L., Miller, Z. A., Garrett, C., La, A., Boxer, A. L., Houde, J. F., Miller, B. L., Vossel, K. A., Gorno-Tempini, M. L., \& Nagarajan, S. S. (2017). Distinct spatiotemporal patterns of neuronal functional connectivity in primary progressive aphasia variants. Brain, 140(10), 2737-2751. https://doi.org/10.1093/brain/awx217

Ravizza, S. M., Delgado, M. R., Chein, J. M., Becker, J. T., \& Fiez, J. A. (2004). Functional dissociations within the inferior parietal cortex in verbal working memory. NeuroImage, 22(2), 562-573. https://doi.org/10.1016/j.neuroimage.2004.01.039

Roach, A., Schwartz, M. F., Martin, N., Grewal, R. S., \& Brecher, A. (1996). The Philadelphia Naming Test: Scoring and rationale. Clinical Aphasiology, 24, 121-133.

Rogalsky, C., Basilakos, A., Rorden, C., Pillay, S., LaCroix, A. N., Keator, L., Mickelsen, S., Anderson, S. W., Love, T., Fridriksson, J., Binder, J., \& Hickok, G. (2020). The Neuroanatomy of Speech Processing: A Large-Scale Lesion Study [Preprint]. Neuroscience. https://doi.org/10.1101/2020.04.02.022822

Rogalsky, C., \& Hickok, G. (2011). The Role of Broca's Area in Sentence Comprehension. Journal of Cognitive Neuroscience, 23(7), 17. 
Rogalsky, C., LaCroix, A. N., Chen, K.-H., Anderson, S. W., Damasio, H., Love, T., \& Hickok, G. (2018). The Neurobiology of Agrammatic Sentence Comprehension: A Lesion Study. Journal of Cognitive Neuroscience, 30(2), 234-255. https://doi.org/10.1162/jocn_a_01200

Rogalsky, C., Matchin, W., \& Hickok, G. (2008). Broca's area, sentence comprehension, and working memory: An fMRI study. Frontiers in Human Neuroscience, 2, 1-13. https://doi.org/10.3389/neuro.09.014.2008

Rohrer, J. D., Caso, F., Mahoney, C., Henry, M., Rosen, H. J., Rabinovici, G., Rossor, M. N., Miller, B., Warren, J. D., Fox, N. C., Ridgway, G. R., \& Gorno-Tempini, M. L. (2013). Patterns of longitudinal brain atrophy in the logopenic variant of primary progressive aphasia. Brain and Language, 127(2), 121-126.

https://doi.org/10.1016/j.bandl.2012.12.008

Sapolsky, D., Bakkour, A., Negreira, A., Nalipinski, P., Weintraub, S., Mesulam, M.-M., Caplan, D., \& Dickerson, B. C. (2010). Cortical neuroanatomic correlates of symptom severity in primary progressive aphasia. Neurology, 75(4), 358-366. https://doi.org/10.1212/WNL.0b013e3181ea15e8

Sonty, S. P., Mesulam, M.-M., Thompson, C. K., Johnson, N. A., Weintraub, S., Parrish, T. B., \& Gitelman, D. R. (2003). Primary progressive aphasia: PPA and the language network. Annals of Neurology, 53(1), 35-49. https://doi.org/10.1002/ana.10390

Sonty, S. P., Mesulam, M.-M., Weintraub, S., Johnson, N. A., Parrish, T. B., \& Gitelman, D. R. (2007). Altered Effective Connectivity within the Language Network in Primary Progressive Aphasia. Journal of Neuroscience, 27(6), 1334-1345. https://doi.org/10.1523/JNEUROSCI.4127-06.2007

Stowe, L. A., Haverkort, M., \& Zwarts, F. (2005). Rethinking the neurological basis of language. Lingua, 115(7), 997-1042. https://doi.org/10.1016/j.lingua.2004.01.013

Thothathiri, M., Kimberg, D. Y., \& Schwartz, M. F. (2012). The Neural Basis of Reversible Sentence Comprehension: Evidence from Voxel-based Lesion Symptom Mapping in Aphasia. Journal of Cognitive Neuroscience, 24(1), 212-222. https://doi.org/10.1162/jocn_a_00118

Tremblay, P., \& Dick, A. S. (2016). Broca and Wernicke are dead, or moving past the classic model of language neurobiology. Brain and Language, 162, 60-71. https://doi.org/10.1016/j.bandl.2016.08.004

Tyler, L. K., \& Marslen-Wilson, W. (2008). Fronto-temporal brain systems supporting spoken language comprehension. Philosophical Transactions of the Royal Society B: Biological Sciences, 363(1493), 1037-1054. https://doi.org/10.1098/rstb.2007.2158

Ullman, M. T. (2016). The Declarative/Procedural Model. In Neurobiology of Language (pp. 953-968). Elsevier. https://doi.org/10.1016/B978-0-12-407794-2.00076-6

Wernicke, C. (1874). The symptom complex of aphasia: A psychological study on an anatomical basis. In R. S. Cohen \& M. W. Wartofsky (Eds.), Boston studies in the philosophy of science (pp. 34-97). D. Reidel Publishing Company.

Wilson, S. M., Brambati, S. M., Henry, R. G., Handwerker, D. A., Agosta, F., Miller, B. L., Wilkins, D. P., Ogar, J. M., \& Gorno-Tempini, M. L. (2009). The neural basis of surface dyslexia in semantic dementia. Brain, 132(1), 71-86. https://doi.org/10.1093/brain/awn300

Wilson, S. M., Dronkers, N. F., Ogar, J. M., Jang, J., Growdon, M. E., Agosta, F., Henry, M. L., Miller, B. L., \& Gorno-Tempini, M. L. (2010). Neural Correlates of Syntactic Processing 
in the Nonfluent Variant of Primary Progressive Aphasia. Journal of Neuroscience, 30(50), 16845-16854. https://doi.org/10.1523/JNEUROSCI.2547-10.2010

Wilson, S. M., Galantucci, S., Tartaglia, M. C., Rising, K., Patterson, D. K., Henry, M. L., Ogar, J. M., DeLeon, J., Miller, B. L., \& Gorno-Tempini, M. L. (2011). Syntactic Processing Depends on Dorsal Language Tracts. Neuron, 72(2), 397-403. https://doi.org/10.1016/j.neuron.2011.09.014

Wilson, S. M., Henry, M. L., Besbris, M., Ogar, J. M., Dronkers, N. F., Jarrold, W., Miller, B. L., \& Gorno-Tempini, M. L. (2010). Connected speech production in three variants of primary progressive aphasia. Brain, 133(7), 2069-2088. https://doi.org/10.1093/brain/awq129

Wilson, S. M., \& Saygın, A. P. (2004). Grammaticality Judgment in Aphasia: Deficits Are Not Specific to Syntactic Structures, Aphasic Syndromes, or Lesion Sites. Journal of Cognitive Neuroscience, 16(2), 238-252. https://doi.org/10.1162/089892904322984535

Yourganov, G., Fridriksson, J., Rorden, C., Gleichgerrcht, E., \& Bonilha, L. (2016). Multivariate Connectome-Based Symptom Mapping in Post-Stroke Patients: Networks Supporting Language and Speech. The Journal of Neuroscience, 36(25), 6668-6679. https://doi.org/10.1523/JNEUROSCI.4396-15.2016 